\title{
Translation and Openness: an Introduction
}

Marta García González, Peter Sandrini

University of Vigo, Spain, University of Innsbruck, Austria

Openness includes removing barriers, taking away limits in order to allow access to and use of knowledge, content, data and software, as well as permitting sharing and collaboration. Openness implies transparency, something open is transparent for users, something that can be reproduced or verified, and something that doesn't conceal anything. When commercial interests are involved openness also means that these interests must be disclosed, they should be clear to users.

A trend towards a more collaborative society can generally be observed. Kennedy (2011), for example, describes three stages of social development, "corresponding very roughly to the first half of the 20th century (A), the latter half of the 20th century (B) and the beginning of the 21st century (C)" (Kennedy 2011: 6):

\begin{tabular}{|c|c|c|}
\hline (A) Traditional & (B) Contemporary & (C) Emergent \\
\hline rationalist economics & behavioural economics & knowledge society \\
\hline rational & romantic & criticality \\
\hline highly structured & neo-liberalism & distributed knowledge \\
\hline top down & soft power & collaboration \\
\hline centralisation & decentralisation & micro-agency \\
\hline nationism/nationalism & globalisation & diversity \\
\hline state power & localisation & public/private partnership \\
\hline predictability & uncertainty & fuzziness/complexity \\
\hline massproduction 'Fordism' & choice/market driven & mobility/flexibility \\
\hline stratified society & less stratified society & multiple identities \\
\hline collectivist cultures & individualism & participation \\
\hline
\end{tabular}

We cannot go into detail here, but the overall development tendency is "one from simplicity to complexity; from mono- to multi-dimensions; from structure to fluidity; from macro to micro" (Kennedy 2011: 7). With all these evolving trends, openness plays a key role, as a catalyst or facilitator. A knowledge society building upon distributed knowledge needs collaboration between the single actors, as well as access to knowledge for all people involved. Social roles shaped by diversity, flexibility and fuzziness are by definition open, and multiple identities, mobility and diversity inevitably presuppose an unprejudiced and open mindset. 
The general notion of a free and open society gained a foothold in many branches of society: from ICT and technology with the concept of Free Software and the Digital Commons, law with open licenses such as the Creative Commons and the Copyleft licenses, pedagogy with the concept of Open Education and the sharing of educational resources (OER, MOOC), to public administration and the idea of Freedom of Information for public documents and processes put into practice by Open Government and Open Data, as well as research with the idea of Open Knowledge and Open Access. At the center of this trend stands the sharing of ideas and the vision of an open and free society and culture (e.g. Free Culture, Open Society Foundation).

Translation as social activity and Translation Studies (TS) as an academic discipline cannot elude those general tendencies. In fact, when we apply the characteristics of the emergent society (C) to translation we will see that many of these features are at the center of modern developments: participation and collaboration refer to participatory forms of translation (Cronin 2013; O'Hagan 2011) such as fansubbing, crowd translation, and all other types of voluntary translation listed in Desilets/van der Meer (2011: 29); multiple identities, flexibility, micro-agency lead us to the consolidation of the exciting branch of researching the sociological foundations of translation (Diaz-Fouces and Monzó 2010; Wolf and Fukari 2007); while the importance of knowledge, the role of the translator within a knowledge society, and distributed knowledge have been recognized widely in LSP translation (Budin and Lušicky 2014; Dam 2005) on the one hand, and in translation technology with the impact of the Internet on knowledge resources and translation data (Chan 2015), on the other hand.

Trying to define openness is not a trivial task: we may refer to the open definition website (opendefinition.org) where openness is defined in the context of open data, open content and open knowledge: "Knowledge is open if anyone is free to access, use, modify, and share it - subject, at most, to measures that preserve provenance and openness" (open definition, version 2.0); or refer to the concept of openness as used by the Free Software Foundation in describing free software and its use where they speak of four essential freedoms granted to users of free software:

- The freedom to run the program as you wish, for any purpose (freedom 0).

- The freedom to study how the program works, and change it so it does your computing as you wish (freedom 1 ). Access to the source code is a precondition for this.

- The freedom to redistribute copies so you can help your neighbor (freedom 2). 
- The freedom to distribute copies of your modified versions to others (freedom 3). By doing this you can give the whole community a chance to benefit from your changes. Access to the source code is a precondition for this (gnu.org).

Free and open may not be used as synonyms, however. There was a long controversy going on between the Free Software Foundation and the Open Source Initiative about the very meaning of free and the ideology associated with it (Raymond 1999); eventually, it appeared that free means much more than open in the context of software, with the free software advocates insisting on freedom as the overall leitmotif and the more pragmatic Open Source followers emphasizing collaboration. Leaving aside ideological debates, we concentrate on using open and openness for the purpose of describing collaborative and free-availability behavior within translation.

Still, the concept of openness is a complex and multifaceted phenomenon touching many aspects of an activity or subject field. In particular, openness encompasses a range of topics (Educause 2009):

- Open standards and interoperability

- Open and community source software development

- Open access to research data

- Open scholarly communications

- Open access to, and open derivative use of, content.

For all these aspects, some initiatives or activities in translation can be found. According to a 2010 study (Gough 2011), 26\% of translators explicitly endorse the "latest trends of sharing, openness and collaboration" (Gough 2011: 211) with more than $50 \%$ expressing a future commitment to these trends. While this study refers to practicing translators we may observe similar trends also in the academic world of translation studies.

Although in the field of translation and translation studies openness can be addressed from different perspectives, two lines of research have attracted particular attention in recent years, namely the study of open standards and formats in translation (Reineke 2005; Mata 2008) and the increasing movement towards open and collaborative forms of translation (O'Hagan 2011).

The use of open standards and formats in translation is relevant not only when connected to the actual behavior of professional translators (García González 2008), but also as a key element in translator training. As claimed by Mata (2008: 75-76), being familiar with the most common open standards and formats contributes to understand the importance and benefits of compatibility and interoperability of CAT tools and helps future translators to 
informedly choose among the available tools based on their need and not only on the requirements of their customers.

Translation technology and the development of CAT tools is not any longer restricted to commercial providers as collaboratively organized open source projects are beginning to enter the desktop of professional translators and translator trainers. Translation memory systems, machine translation applications, text alignment tools, software localization programs, subtitling tools, text alignment and terminology tools, as well as translation management applications already exist as open source programs or free software. In many cases, users may even choose between two or more alternative packages. Openness in this respect not only facilitates access to such software applications or switching between different programs without any costs involved, it also enables users to contribute to these projects and to become part of a community.

Communities of users have evolved who regularly translate texts, documentation, film dialogues on a voluntary basis (O'Brien and Schäler 2010). These may be fan groups of television series or movies translating subtitles into many languages and sharing the translations on-line (fansubbing, fandubbing), fans of video games or users of free software who contribute to the projects by translating user interfaces or documentation material. Even companies with a large user base have begun to outsource the translation of their websites or on-line forums to their users (crowd-sourcing, user-generated translation) to economize on costs and time. These kind of translation done by lay people without any kind of specific training has become an object of study by the academic world with researchers investigating the efficiency and quality of their work, but also their impact on the professional world of translation (Olohan 2014; McDonough Dolmaya 2011 and 2012).

On the other hand, professional translators have begun to rediscover their ethical side and participate in voluntary translation work for NGOs. Some even have formed translation networks to deal with the large demand for translations by charitable bodies (e.g. Translators without Borders, The Rosetta Foundation, Mondo Lingua Initiative, Translators and Interpreters for Solidarity ECOS, Babels). On-line volunteer translators can be classified by their formal qualification, but also by their motivation and approach to translation, as done, for example, in Bey et al (2008: 136):

1. Mission-oriented translator communities: strongly-coordinated groups of volunteers involved in translating clearly defined sets of documents, mostly technical documentation. 
2. Subject-oriented translator network communities: individual translators who translate on-line documents such as news, analyses, and reports and make translations available on personal or group web pages.

In many cases of volunteer translation we may observe a trend to "demonetization and deprofessionalization of translation" (Olohan 2014: 18) which is why openness is strongly opposed by many professional translators who strive to earn their living from translation. In view of these persisting and increasing trends, however, a lock-down or defensive attitude should give way to a more viable diversification and differentiation of translation as an activity.

The advantages of openness have been recognized also in the world of academia where the growing costs for journal subscriptions and publishers have begun to raise barriers for research. It is clear that research can thrive only when based upon other research, and thus, unrestricted on-line access to scholarly research is a necessary requirement. In March 2015, UNESCO launched its Open Access Curriculum, a set of manuals to facilitate capacity building of library and information professionals and researchers, as part of its Strategy on open access to scientific information and research. And we may observe a growing trend in academic translation journals to publish in an open access format as described in two contributions in this volume, so that open access to scholarly literature is beginning to gain a foothold also in translation studies.

Openness includes open access to, and open derivative use of content, in our case of translations. Translation technology and translation data allow the re-use of previously done translations on a broad scale, as implemented by statistical machine translation and translation memory systems. In the professional world of translation this has raised a number of questions, such as, for example, who owns a translation memory, how much price reduction can be applied in cases of a translation match of whatever percentage from a client-supplied translation memory, or what compensation should be paid when the translator is providing her translation memory to the client. It seems that in this case we are witnessing a conflict about who will be the ultimate beneficiary of economies of scale in translation. There is no doubt, however, that open content and open access to translation resources is important, especially in the context of official translations. Translations done by official institutions entirely financed from public funds should be made publicly available, not just as translated texts but also in the form of translation memories wherever available. Open access to translation data, thus, can be a part of an Open Government and Open Data strategy. 
Contributions to this volume review some of the above referred topics, such as FOSS for translators and the training of translators with FOSS applications, or the open access to scholarly literature but also cover some other topics connected to the study of openness as it is quality, both quality of FOSS for translators and quality of volunteer and collaborative translations. Full coverage of all topics regarding openness in translation is beyond an anthology like this, the whole concept of openness is simply too varied and challenging.

Nevertheless, the volume falls into three thematic sections: the first and most substantial part deals with the concept of openness in ICT (open data, open tools, open computer systems, and quality evaluation of open software), the middle part is concerned with translators training and the use of open software, and the last part discusses openness in academia on the basis of the concepts of Digital Scholarship and the 'Scientist 2.0'.

The volume opens with a critical discussion of the concepts of openness and closedness/proprietariness as they relate to the assemblages of data, knowledge and information that result from the practice of professional translation. Philipp Neubauer underlines the fact that neither concept can be considered as existing in a vacuum, and that both need to be seen to play out against the background of social and technological change in society in general and a notable power differential between the suppliers and providers of translation services in particular. Special attention is to be drawn to the emergence of unintended consequences which may accompany processes of both "open sourcing" and appropriation of said resources.

Cristian Lakó then describes a methodology which takes freely available open tools on the web to set up a list of most used keywords relevant for the target audience. Thus, the profiling of the reader is no longer constructed on rather random data but on hard statistical evidence, and the target text, especially websites and other marketing oriented texts, is more likely to be found by the web-users of the target market, thus facilitating organic B2C communication.

In the third contribution, Peter Sandrini investigates why and how the free operating system GNU/Linux is suitable as a platform for multilingual text production and translation by outlining the rationale behind their development and their historical evolution. He presents several specific initiatives and examples of GNU/Linux based open desktop systems for translators and discusses potential reasons why a wider adoption in the translation community has not yet taken place.

Potential users of open-source translation technologies face the daunting task of considering the available options and selecting the one that better 
satisfies their needs. Silvia Flórez and Amparo Alcina propose a quality model for the evaluation of open-source translation technologies going beyond software product evaluation and including aspects of the communities and processes that sustain development projects. Evaluation instruments and results are publicly available on-line.

Evaluation is also at the center of the following contribution: after a short over-view of the phases and results of the research project Creación dunha plataforma docente GNU/LINUX para a formación de tradutores - localizadores de software - subtituladores, funded by Xunta de Galiza, within the framework of programme Incite, Maite Veiga Díaz and Marta García González describe a particular research effort devoted to the testing of the usability of free and open-source translation memory managers and text aligners with different types of texts, and their applicability to translator training. This represents a smooth transition to the next topic of the volume, namely openness in a didactic context and specifically, translators training.

Approaches to process-oriented translator training can be optimized using freeware and FOSS screen recording technology. Screen recording technology captures all activity that transpires on-screen over the course of task completion in the form of a video that can be analyzed in a retrospective fashion for purposes of enhancing problem and problem-solving awareness, among other things. In addition to describing how to best utilize various features inherent to freeware and FOSS screen recording applications, Eric Angelone also presents a series of concrete learning activities as a groundwork guide for process-oriented training.

Adrià Martín-Mor, Ramon Piqué Huerta and Pilar Sánchez-Gijón from the Tradumàtica group show how openness is becoming a key concept in translation through a case in point: the collaboration between the Tradumàtica Masters (Translation Technologies) and the Public Knowledge Project (PKP) to localise their academic software (Open Journal Systems and Open Monograph Press) into Spanish and Catalan. This intersection between openness, translators training and open access publication options brings us to the last thematic division of the book which is openness in research and the academia.

The most important research tools, archives, libraries, research centers and universities make use of the central features of the web represented by the opportunity to save time and costs with connecting a wide variety of content through linking. These emerge also as advantages in scientific publishing where such trends seem to be able to revolutionize research and scientific publishing activity. While open publishing and transparency seem to find more followers in the natural sciences, they are still far from being broadly accepted in the humanities, especially within the philologies. In his contribution, Marco 
Agnetta describes the concept of a "Scientist 2.0" and investigates current opinions about open access that can be relevant for the self-conception of a future translatology by identifying strengths and weaknesses in positive and negative attitudes towards open access.

In the last contribution to the volume, Peter Sandrini gives an overview over digital scholarship in translation studies by examining publication methods and academic evaluation approaches where open initiatives and commercial activities confront each other. The author makes a plea for openness since more openness could very well foster the discipline of translation studies as a whole and move it towards a more unified and collaborative field of study.

Authors and editors have teamed up to put together a list of bibliographical references that aims at covering the different topics of openness and translation, a rather difficult task since such a compilation can never be exhaustive nor complete. The resulting list under the heading "Further Literature and Useful Readings" includes 179 references which may be subdivided into four sections:

- $\quad$ open tools (in translation) (82)

- $\quad$ open access (in translation studies) (7)

- $\quad$ open standards and formats (in translation) (9)

- $\quad$ open and collaborative translation (83)

Each reference is tagged with one or multiple keywords from this classification so that readers may identify which topic is covered. The digital version of the list of references (see web page at http://www.petersandrini.net/ transopen.html) in BibTeX format allows for an automatic extraction of references according to a specific subfield; for this volume, however, an alphabetical arrangement was chosen because multiple categorizations would not be possible in the printed medium.

While openness regarding translation technology, or the development and adoption of open standards and formats may represent a rather clear-cut subject, for different reasons this is not the case with open and collaborative translation and open access in translation studies. Open and collaborative translation represents a very heterogeneous subject field including such diverse topics as community translation, user-generated translation, volunteer translation, crowd-sourcing of translation, and fan translation, fansubbing, fandubs, scanlators, etc. (for a detailed discussion of these concepts, their definitions and overlapping areas see O'Hagan 2011: 13-16). Moreover, this field of study has generated great interest among researchers and a lot of relevant 
publications exist. Since this does not constitute the main topic of this volume, nor is it the goal of this compilation of references to cover all aspects of collaborative translation, we concentrated on the aspect of openness within this broad range of topics.

For a different reason, open access in translation studies represents another problematic classification. Much has been published about open access in general, but, unfortunately, very little related specifically to openness and open access in translation studies. Compiling a list of references, thus, represents a tedious task.

A chapter with short biographical notes on authors and a keyword index close the book.

We hope that readers will find this volume informative and that they will make use of the references given in order to further develop ideas and thoughts expressed in the contributions. As editors of this volume we are convinced that thinking about openness and implementing openness in our attitudes and actions have considerable bearing on our conception of ourselves as translators or researchers. Openness indeed questions the very role of translated texts, multilingual translation resources, the ethics of translators, their professional behavior, the self-conception of academics and researchers, as well as the role and availability of research results in society. Furthermore, openness challenges traditional commercial models both for professional translation and for academic publishing. It therefore constitutes one of the most stimulating challenges that the world of professional translation and translation studies have yet faced.

\section{Acknowledgements}

Our deep-felt thanks go out to the free and open source projects active in the field of translation, as well as to all involved individuals for their effort, motivation, time and resources dedicated to these activities, without whom all of this would not be possible.

We would like to thank the authors for their cooperation and good grace in providing their contributions in conformity with our requirements. Our thanks are due also to innsbruck university press for the smooth and frictionless publication of this volume.

\section{References}

Bey, Y., Boitet, C. and Kageura, K. (2008) The TRANSBey Prototype: An Online Collaborative Wiki-based CAT Environment for Volunteer Translators. In Yuste Rodrigo, E. (ed.) 
Topics in Language Resources for Translation and Localisation. Amsterdam: John Benjamins, 135-150.

Budin, G. and Lušicky, V. (2014) Languages for Special Purposes in a Multilingual, Transcultural World. Proceedings of the 19th European Symposium on Languages for Special Purposes, 8-10 July 2013, Vienna, Austria. Available at:

http://lsp2013.univie.ac.at/ proceedings [Accessed 10 August 2015].

Chan, Sin-wai (ed.) (2015): The Routledge encyclopedia of translation technology. London: Routledge.

Cronin, M. (2013) Translation in the digital age. London: Routledge.

Currie, C. (2009) What Is Openness, Anyway? EDUCAUSE Quarterly. Available at: http://www.educause.edu/ero/article/what-openness-anyway [Accessed 10 August 2015].

Dam, H. V. (ed.) (2005) Knowledge systems and translation. Berlin: Mouton de Gruyter.

Désilets, A. and van der Meer, J. (2011) Co-creating a repository of best-practices for collaborative translation. In Linguistica Antverpiensia 10, 27-46. Available at: https://lans-tts.ua.ac.be/index.php/LANS-TTS/article/view/276 [Accessed 10 August 2015].

Diaz-Fouces, O. and Monzó, E. (2010) What would a sociology applied to translation be like? In MonTI 2, 9-18. Available at: http://rua.ua.es/dspace/bitstream/10045/16432/1/ MonTI_2_01.pdf [Accessed 18 September 2015].

EDUCAUSE Review (2009) EDUCAUSE Values: Openness, January/February 2009. Available at: http://www.educause.edu/ero/article/educause-values-openness [Accessed 10 August 2015].

Garcia, M. (2008) Free software for translators. Is the market ready for a change, In Diaz Fouces, O. and García, M. (eds.) Traducir (con) software libre. Granada: Comares, 931.

Gough, J. (2011) An empirical study of professional translator's attitudes, use and awareness of Web 2.0 technologies, and implications for the adoption of emerging technologies and trends, In O'Hagan, M. (ed.) Translation as a Social Activity - Community Translation 2.0, Linguistica Antverpiensia 10/2011, 195-217.

Kennedy, C. (2011) Challenges for language policy, language and development. In Coleman, H. (ed.) Dreams and realities: developing countries and the English Language. London: British Council. Available at: https://www.teachingenglish.org.uk/ sites/teacheng/files/Z413\%20EDB\%20Section02_0.pdf [Accessed 10 August 2015].

Mata Pastor, M. (2008) Formatos libres en traducción y localización. In Diaz Fouces. O. and García, M. (eds.) Traducir (con) software libre. Granada: Comares, 75-122.

McDonough Dolmaya, J. (2011) Wikipedia survey IV (motivations). Some thoughts on translation research and teaching. Available at: http://mcdonoughdolmaya.ca/2011/08/24/wikipedia-survey-iv-motivations/ [Accessed 10 August 2015].

McDonough Dolmaya, Julie (2012): Analyzing the crowdsourcing model and its impact on public perceptions of translation. The Translator 18, no. 2, 167-191.

O'Hagan, M. (2011) Community Translation: Translation as a social activity and its possible consequences in the advent of Web 2.0 and beyond. In Linguistica Antverpiensia. 10, 1-10. 
O'Brien, S.; Schäler, R. (2010) Next generation translation and localization: Users are taking charge. Paper presented at Translating and the computer 32, London, November, 18-19. Available at http://doras.dcu.ie/16695/1/Paper_6.pdf [Accessed 10 August 2015].

Olohan, M. (2014) Why do you translate? Motivation to volunteer and TED translation, Translation Studies, 7:1, 17-33.

Raymond, E. (1999) The Cathedral and the Bazaar: Musings on Linux and Open Source by an Accidental Revolutionary. Boston: O'Reilly Media.

Reineke, D. (2005) XMK en la traducción, en Reineke, D. (ed.) Traducción y localización: mercado, gestión y tecnologías. Las Palmas: Anoart Ediciones, 285-315.

Wolf, M. and Fukari, A. (eds.) (2007) Constructing a Sociology of Translation. Amsterdam: John Benjamins Publishing Company. 
